\title{
Comparative study of fine needle aspiration cytology and histopathology in diagnosis of neck swellings
}

\author{
Manish Kumar ${ }^{1}$, Manjeet Singh ${ }^{2 *}$
}

${ }^{1}$ Senior Resident, Department of ENT, Nalanda Media College and Hospital, Patna, Bihar, INDIA.

${ }^{2}$ ENT Surgeon, Department of ENT, RPGMC Kangra at Tanda, Himachal Pradesh, INDIA.

Email: bittusony@gmail.com, manjeetst@gmail.com

\begin{abstract}
Background: Fine Needle Aspiration Cytology (FNAC) is a simple, quick and inexpensive method that is used to diagnosed neck swellings. It causes minimal trauma to the patient and carries virtually no risk of complications. Aim: To compare fine needle aspiration cytology and histopathology in diagnosis of neck swellings. Material and Methods: A total 54 patients of either sex presented with the neck swelling were included in the study. FNAC diagnosis was made and after surgery it was compared with final histopathology diagnosis. Results: Most of the cases were benign (52\%), malignant lesions were $(23 \%)$. Rest $(25 \%)$ lesions were inflammatory. FNAC and Histopathology was correlating in about $(70 \%)$ of the cases of the neck swelling. $100 \%$ correlation was found in acinic cell carcinoma, metastatic squamous cell carcinoma, lipoma, inflammatory lesions, pleomorphic adenoma, reactive lymphadenitis, follicular and medullary neoplasm of thyroid. Zero percent correlation was found in the abscess, schwanoma, mucoepidermoid carcinoma. Conclusion: FNAC is recommended as a safe and reliable technique in diagnosis of thyroid and non-thyroidal head and neck lesions. It is a quick, convenient, inexpensive, easy to carry out in the office and should be considered as a first line investigation in evaluation of the swelling of head and neck.
\end{abstract}

Key Words: Neck swelling, fine needle aspiration cytology, histopathology, correlation

*Address for Correspondence:

Dr. Manjeet Singh, ENT Surgeon, Department of ENT, RPGMC Kangra at Tanda, Himachal Pradesh, INDIA.

Email: manjeetst@gmail.com

Received Date: 21/10/2019 Revised Date: 09/11/2019 Accepted Date: 16/12/2019

DOI: https://doi.org/10.26611/10161311

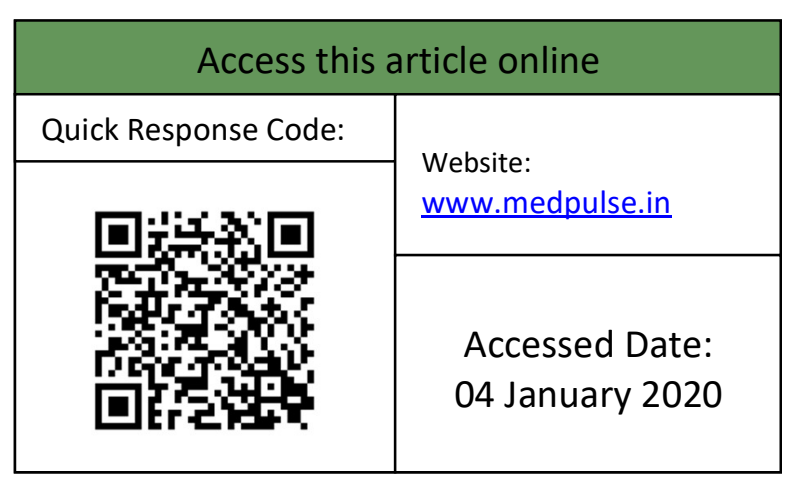

\section{INTRODUCTION}

Neck swelling is an accumulation of fluid in the neck tissues or inflammation in the neck or due to abnormal proliferation of the normal tissue. There are several different types of neck lumps, with causes ranging in severity from mild to life-threatening. Benign and malignant tumors mainly neurogenic tumors may present as neck swelling. With the exception of masses that occur in the thyroid, $80 \%$ of adult neck masses were neoplastic and $80 \%$ of those are malignant. ${ }^{1}$ The diagnostic accuracy of FNAC depends on several factors, including the site and type of lesion, the experience of the aspirator, the quality of the specimen preparation and the diagnostic skills of the cytopathologist. ${ }^{2}$ In the present study we intended to find out the easiest and effective method to diagnose the swelling in the neck. The present study was conducted to compare fine needle aspiration cytology and histopathology in diagnosis of neck swellings.

\section{MATERIAL AND METHODS}

The study was conducted in the Department of ENT and Department of Pathology of a tertiary care hospital after taking permission from protocol review committee and institutional ethical committee.

All the patient attending the department of ENT with complaint of neck swelling or complication of neck swelling, over a period of 12 month fulfilling the 
inclusion and exclusion criteria were included in the study.

\section{Inclusion criteria}

- Patients with complaints of neck swelling or complications of neck swelling.

\section{Exclusion criteria}

- Patients not willing to participate in the study.

- Patients with cardiovascular instability.

- Patient with bleeding diathesis or deranged coagulation profile.

- Patient with subclinical neck swelling.

- Patient with advanced staged carcinoma of neck, have previously diagnosed and treated.

- Patient with carotid body tumors.

\section{Methodology}

Patient was explained about the complete study procedure. After taking written informed consent, detailed history and clinical examination of patient was elicited with special emphasis on neck swelling problem. A thorough systemic examination was done to rule out any other systemic disease. After cleaning the part with antiseptic by using a needle of $23 \mathrm{G}$, the swelling was held firmly with the left hand and inserted the needle in the different direction while aspirating the material. The same was done under ultrasound guided FNAC. After this slide was prepared and stained with HandE and submitted to the cytotechnologist for screening. Process was repeated if there was insufficient sample on the slide. When multiple swellings were palpable then the procedure was performed on the largest one. Regarding generalized lymphadenopathy, cervical lymph node biopsy was considered superior to axillary and inguinal region. Apart from FNAC and Histopathology, the diagnosis of the various neck swelling was also supported by various radiological tools like USG, C.T. Scan or possibly M.R.I. Detailed ear, nose and throat examination was performed in each case. At this point of time the decision was made whether patient should undergo simply medical treatment or undergo surgical treatment. The patients undergoing surgical procedure for the removal or simply for the biopsy were included in the present study. After making the provisional diagnosis from FNAC and various other radiological methods, postoperative histopathological examination was done to confirm and treat the patient as well. We sent the specimen for the histopathology.

\section{Statistical analysis}

The data were recorded on a predesigned proforma and analyzed statistically. It was analyzed using EpiInfo version-6 software. The sensitivity, specificity and predictive values of the test were calculated.

\section{RESULTS}

A total 54 patients of either sex presented with the neck swelling were included in the study and their demographic profile, clinical presentation studied followed by FNAC and postoperative histopathology were studied. The most common age group in the present study was $41-60$ years $(46.29 \%)$ of age. Followed by 21 40 years $(28 \%)$ of age. Age group 11-20 years and 61-80 years constitute only $9 \%$. In the current study $34(63 \%)$ were female and $20(37 \%)$ were male. Maximum numbers of the patient (31.5\%) have neck swelling since 6 -months duration. Those having neck swelling since 1 year comprises of $27 \%$ of the case. $14 \%$ have neck swelling of 1-2 years duration. While around $10 \%$ have swelling of less than one-month duration.

\begin{tabular}{ccc}
\multicolumn{4}{c}{ Table 1: Location of the neck swelling } \\
\hline Location of Swelling & No. of cases & Percentage (\%) \\
\hline Midline of neck & 4 & 7.4 \\
Right side of neck post. triangle & 1 & 1.9 \\
Right side of neck ant. triangle & 11 & 20.4 \\
Right side of neck parotid region & 10 & 18.5 \\
Right side of neck over scm & 3 & 5.6 \\
Right side submandibular region & 5 & 9.3 \\
Left side of neck post. triangle & 7 & 13 \\
Left side of neck ant. triangle & 2 & 3.7 \\
Left side of neck parotid region & 3 & 5.6 \\
Left side of neck over scm & 5 & 9.3 \\
Left side submandibular & 1 & 1.9 \\
Right side multiple swelling & 1 & 1.9 \\
Midline and right & 1 & 1.9
\end{tabular}

The maximum number of the patient (20\%) presented with the swelling in the right anterior triangle. Next commonest swelling presentation was in the parotid region right side which comprises $(18.5 \%)$. 
Table 2: Frequency and percentage of tissue involved in the neck swelling

\begin{tabular}{ccc}
\hline Organ involved & Frequency & Percentage (\%) \\
\hline Thyroid & 19 & 35.2 \\
Parotid & 12 & 22.2 \\
Lymph node & 2 & 3.7 \\
Submandibular gland & 9 & 16.7 \\
Subcutaneous tissue & 11 & 20.4 \\
Deep neck space & 1 & 1.9 \\
\hline
\end{tabular}

In the current study most of the swelling was arising from the thyroid tissue (35\%). Next was from parotid (22\%), subcutaneous tissue (20\%), submandibular gland (17\%). Lymph nodes and the deep neck space constitute (4\%) and (2\%) respectively.

Table 3: Frequency and percentage of the FNAC diagnosis

\begin{tabular}{cccc}
\hline S.N. & Diagnosis on FNAC & No. of cases & Percentage \\
\hline 1 & Papillary carcinoma of thyroid & 03 & 5.6 \\
2 & Medullary carcinoma of thyroid & 01 & 1.9 \\
3 & Follicular adenoma of thyroid & 03 & 5.6 \\
4 & Reactive lymphadenitis & 03 & 5.6 \\
5 & Sialoadenitis & 03 & 5.6 \\
6 & Pleomorphic adenoma & 11 & 20.4 \\
7 & Abcess & 04 & 7.4 \\
8 & Lymphocytic thyroiditis & 01 & 1.9 \\
9 & Benign cyst & 02 & 3.7 \\
10 & Inflammatory & 02 & 3.7 \\
11 & Adenomatous goiter & 16.7 \\
12 & MNG, colloidal goiter, cystic nodule of thyroid & 09 & 1.9 \\
13 & Adenocarcinoma & 01 & 1.9 \\
14 & Oncocytoma & 01 & 1.9 \\
15 & Granulomatous lymphadenitis & 01 & 3.7 \\
16 & Non conclusive & 02 & 1.9 \\
17 & Lipoma & 01 & 1.9 \\
18 & Metastatic squamous cell carcinoma & 01 & 1.9 \\
19 & Non Hodgkin's lymphoma & 01 & 1.9 \\
20 & Warthim's tumor & 01 & 1.9 \\
21 & Acinic cell carcinoma & 01 & 1.9 \\
22 & Adenoid cystic carcinoma & 01 & 1.9 \\
\hline
\end{tabular}

Most of the swelling was from pleomorphic adenoma (about 20\%). Then next was goiter about (17\%), followed by abscess (7.4\%), papillary carcinoma of thyroid, follicular adenoma of thyroid, reactive lymphadenitis, sialoadenitis all constitute $(5.6 \%)$.

Table 4: Frequency and percentage of the Histopathology diagnosis

\begin{tabular}{cccc}
\hline S.N. & Diagnosis on Histopathology & No. of cases & Percentage \\
\hline 1 & Papillary carcinoma of thyroid & 04 & 7.4 \\
2 & Medullary carcinoma of thyroid & 01 & 1.85 \\
3 & Follicular adenoma of thyroid & 02 & 3.70 \\
4 & Reactive lymphadenitis & 02 & 3.70 \\
5 & Sialoadenitis & 04 & 7.4 \\
6 & Pleomorphic adenoma & 11 & 20.37 \\
7 & Abcess & 01 & 1.85 \\
8 & Benign cyst & 03 & 5.55 \\
9 & Inflammatory & 02 & 3.70 \\
10 & Adenomatous goiter, MNG, colloidal goiter, cystic nodule of thyroid & 11 & 20.37 \\
11 & Granulomatous lymphadenitis & 02 & 3.70 \\
12 & Non conclusive & 03 & 5.55 \\
13 & Lipoma & 01 & 1.85 \\
14 & Metastatic squamous cell carcinoma & 01 & 1.85 \\
15 & Warthim's tumor & 02 & 3.70 \\
16 & Mucoepidermoid carcinoma & 02 & 3.70 \\
17 & Schwanoma & 01 & 1.85 \\
\hline
\end{tabular}




\begin{tabular}{lccc}
\hline 18 & Acinic cell carcinoma & 01 & 1.85 \\
19 & Tuberculosis & 01 & 1.85 \\
\hline
\end{tabular}

In the current study, the pleomorphic adenoma, and goiter constitute the maximum number about (20\%). Rest sialoadenitis and papillary carcinoma of the thyroid constitute (7\%). The histopathology was inconclusive in the (6\%) of the cases. (6\%) was benign cyst. follicular adenoma of thyroid, reactive lymphadenitis, warthim's tumor, mucoepidermoid carcinoma, granulomatous lymphadenitis, inflammatory in (4\%) of the cases. Medullary carcinoma of thyroid, schwanoma, tuberculosis, acinic cell carcinoma, metastatic squamous cell carcinoma and abcess constituted about $(2 \%)$ respectively. Most of the swelling in the current study were benign (52\%), malignant lesions were (23\%). Rest $(25 \%)$ lesions were inflammatory. And among the malignant, which was 11 cases, in the 8 cases it detected that it was malignant. i.e. in the $73 \%$ of the malignant cases it had made the diagnosis of the malignant. While in 2 cases which was follicular neoplasm in which FNA can't distinguish between adenoma and carcinoma.

Table 5: Comparison of FNA and histopathology diagnosis

\begin{tabular}{|c|c|c|c|c|}
\hline Histopathology & Not matched & Matched & Total & Accuracy \% \\
\hline Papillary carcinoma of thyroid & 1 & 3 & 4 & 75 \\
\hline Medullary carcinoma of thyroid & 0 & 1 & 1 & 100 \\
\hline Follicular neoplasm of thyroid & 0 & 2 & 2 & 100 \\
\hline Reactive lymphadenitis & 0 & 2 & 2 & 100 \\
\hline Sialoadenitis & 2 & 2 & 4 & 50 \\
\hline Pleomorphic adenoma & 0 & 10 & 10 & 100 \\
\hline Abscess & 1 & 0 & 1 & 0 \\
\hline Benign cyst & 1 & 2 & 3 & 66.7 \\
\hline Inflammatory & 0 & 2 & 2 & 100 \\
\hline Adenomatous goiter, MNG, colloidal goiter, cystic nodule of thyroid & 2 & 9 & 11 & 81.8 \\
\hline Granulomatous lymphadenitis & 1 & 1 & 2 & 50 \\
\hline Non conclusive & 3 & 0 & 3 & 0 \\
\hline Lipoma & 0 & 1 & 1 & 100 \\
\hline Metastatic Squamous cell carcinoma & 0 & 1 & 1 & 100 \\
\hline Warthim's tumor & 1 & 1 & 2 & 50.0 \\
\hline Mucoepidermoid carcinoma & 2 & 0 & 2 & 0.0 \\
\hline Schwanoma & 1 & 0 & 1 & 0.0 \\
\hline Acinic cell carcinoma & 0 & 1 & 1 & 100.0 \\
\hline Tuberculosis & 1 & 0 & 1 & 0.0 \\
\hline Total & 16 & 38 & 54 & 70.4 \\
\hline
\end{tabular}

The incidence of the malignant lesion in the female was more than male. There were 5 cases $(45.45 \%)$ of malignancy was in the male while 6 cases $(54.54 \%)$ out of 11 cases is female. FNAC and Histopathology was correlating in about $(70 \%)$ of the cases of the neck swelling, and non correlating in the remaining $(30 \%)$ of the cases. $100 \%$ correlation was found in acinic cell carcinoma, metastatic squamous cell carcinoma, lipoma, inflammatory lesions, pleomorphic adenoma, reactive lymphadenitis, follicular and medullary neoplasm of thyroid. $82 \%$ correlation was found in the goiter, $75 \%$ correlation was found in the papillary carcinoma of thyroid, $67 \%$ was found in benign cyst, $50 \%$ correlation was found in the warthim's tumor, granulomatious lymphadenitis, sialoadenitis. Zero percent correlation was found in the abscess, schwanoma, mucoepidermoid carcinoma.

\section{DISCUSSION}

In our study, the diagnostic accuracy of FNA in pleomorphic adenoma and acinar cell carcinoma was $100 \%$ while $50 \%$ for sialoadenitis and Warthim's tumor. The sensitivity of the pleomorphic adenoma was $100 \%$, and specificity was $97.7 \%$, positive predictive value was $90.9 \%$, negative predictive value was $100 \%$, and the chisquare value was $50 \%$. There was similar study conducted by Ashraf A et $a l^{\beta}$ on diagnostic reliability of FNAC for salivary gland swellings. In that study $60 \%$ were female and $40 \%$ were male. Parotid gland, $68 / 100$ $(68 \%)$, was the commonest site of involvement followed by submandibular gland, 30/100 (30\%), and minor salivary glands, $2 / 100(2 \%)$. Benign neoplasms were $71 \%$ vs. $68 \%$, whereas malignant neoplasms were $15 \%$ vs. $18 \%$ on FNAC and biopsy, respectively. For neoplastic lesions on FNAC, 71 of 100 (71\%) cases showed features of benign neoplasms, including pleomorphic adenoma in 66 of $71(92.95 \%)$, oncocytic adenoma in 2 of 71 (2.81\%), adenolymphoma in 2 of $71(2.81 \%)$, and lipoma 
in 1 of $71(1.40 \%)$. Fifteen (15\%) cases were diagnosed as malignant neoplasm constituting mucoepidermoid carcinoma in 7 of 15 (46.6\%), acinic cell carcinoma in 3 of $15(20 \%)$, adenoid cystic carcinoma in 2 of 15 (13.3\%), adenocarcinoma in 2 of $15(13.3 \%)$, and nonHodgkin lymphoma in 2 of 15 (13.3\%). Histopathology of neoplastic lesions showed that out of four pleomorphic adenomas on FNAC, two were mucoepidermoid carcinoma, one was pleomorphic adenomas with malignant change, and one was adenoid cystic carcinoma, whereas one adenoid cystic carcinoma on FNAC was found to be pleomorphic adenoma on biopsy. Singh A et $a l^{4}$ also conducted the comparative study of FNA and histopathology in the salivary gland and they found that sensitivity and specificity of cytology were found to be $76.9 \%$ and $97.1 \%$ respectively. Rajbhandari $\mathrm{M}$ et $a l^{5}$ studied the correlation between FNA and histopathology of head and neck lesions. The highest number of cases included lymph nodes $29(45 \%)$ followed by thyroid 24 (37.5\%), salivary glands $10(16 \%)$ and 1 case $(1.6 \%)$ was a soft tissue swelling over the occipital region. Highest sensitivity, specificity and accuracy rate for diagnosis by FNAC were observed in thyroid. Rout $\mathrm{K}$ et $a l^{6}$ conducted a study on 76 cases, out of which 53 cases were females and 23 were males. Among that cases, 73 cases showed positive correlation between FNAC and histopathology. The diagnostic accuracy of FNAC for thyroid swellings in this series was $96.05 \%$. In this study 31 out of 32 cases of colloid goiter diagnosed by FNAC corroborated with histopathology result. 4 out of 6 follicular adenoma, of thyroid diagnosed by FNAC correlated correctly with their histopathological results where as two cases were diagnosed to be follicular carcinoma by histopathological study. 5 cases of papillary carcinoma of thyroid were diagnosed correctly by FNAC. This was comparable with the present study as the diagnostic accuracy for the thyroid on an average is $89 \%$. Three Out of 4 papillary carcinoma, 1 out of 1 medullary carcinoma and 2 out of 2 follicular carcinoma and 9 out of 11 goiter case was diagnosed on FNA. The average diagnostic accuracy of the FNA in the diagnosing the thyroid disorder is $89 \%$. There were total 3 follicular adenoma cases, in which 2 cases reported after histopathology to be follicular carcinoma and one was misdiagnosed as papillary carcinoma.

\section{CONCLUSION}

FNAC is recommended as a safe and reliable technique in diagnosis of thyroid and non-thyroidal head and neck lesions. It is a quick, convenient, inexpensive, easy to carry out in the office and should be considered as a first line investigation in evaluation of the swelling of head and neck.

\section{REFERENCES}

1. Flint PW, Haughey BH, Lund VJ, Niparko JK, Richarson MA, Robbins KT, et al. Differential Diagnosis of Neck Masses. In: Cuming Otorhinolaryngiology Head And Neck Surgery. 5th ed. Philadelphia: Mosby Elsevier; 2010. p. 1637-42.

2. Layfield LJ. Fine-needle aspiration of the head and neck. Pathology (Phila) 1996; 4:409 38.

3. Ashraf A, Shaikh AS, Kamal F, Sarfraz R, Bukhari MH. Diagnostic Reliability of FNAC for Salivary Gland Swellings: A Comparative Study. Diagnostic Cytopathology. 2010;38(7):499-504.

4. Singh A, Haritwal A, Murali BM. Correlation between cytology and histopathology of the salivary gland. Australian Medical Journal AMJ. 2011; 4(2): 66-71.

5. Rajbhandari $\mathrm{M}$ et al. The correlation between fine needle aspiration cytology and histopathology of head and neck lesions in Kathmandu University Hospital. Kathmandu Univ Med J (KUMJ). 2013;11:296- 9.

6. Rout K, Ray CS, Behera SK, Biswal R. A Comparative Study of FNAC and Histopathology of Thyroid Swellings. Ind J Otolaryngol Head Neck Surgery. 2011October-December; 63(4): 370-372.

Source of Support: None Declared Conflict of Interest: None Declared 